\title{
Evaluation of Calcium Alginate Microparticles for Copper Preconcentration prior to F AAS Measurements in Fresh Water
}

\author{
Marcos Bruno Almeida Colombo, Lucas Eduardo Oliveira Porto, Gabriel Gustinelli Arantes de \\ Carvalho, Denise Freitas Siqueira Petri, Pedro Vitoriano Oliveira $\triangle$ (iD
}

Departamento de Química Fundamental, Instituto de Química, Universidade de São Paulo, Av. Prof. Lineu Prestes, 748, 05513-970 São Paulo, SP, Brazil

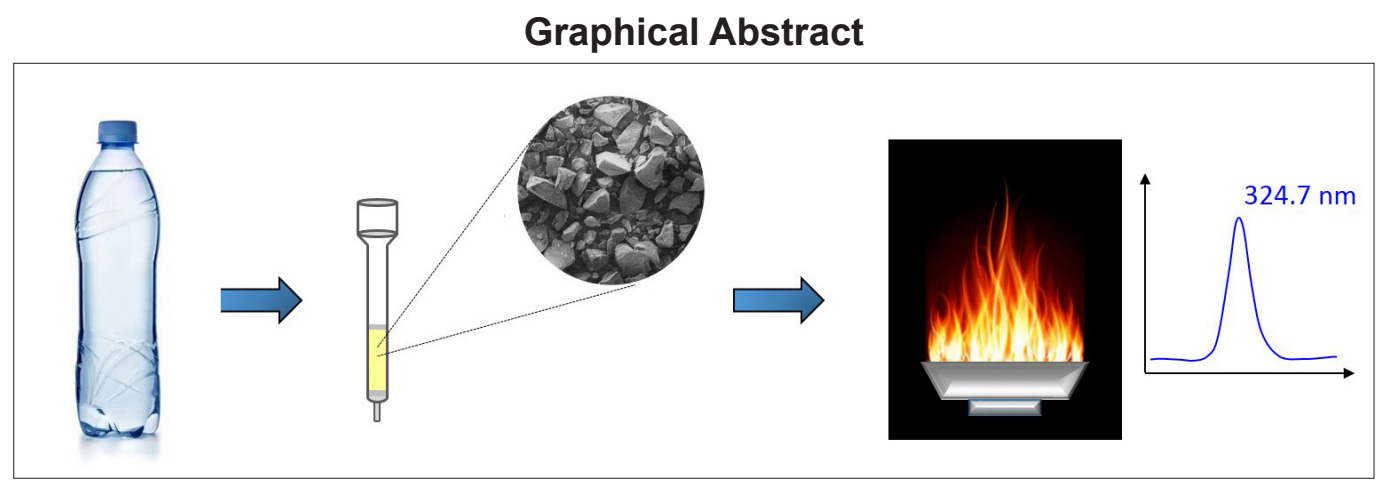

Cu preconcentration for F AAS - Calcium alginate microparticles were used for the preconcentration of copper for F AAS analysis of fresh waters

A method for separation and preconcentration of $\mathrm{Cu}^{2+}$ from fresh waters prior to flame atomic absorption spectrometry (FAAS) measurements, using calcium alginate (CA) microparticles, is proposed. Off-line analytes preconcentration was achieved using a flow-injection system incorporating a column containing CA (< $180 \mu \mathrm{m} ; 300 \mathrm{mg})$. The preconcentration procedure consisted of $50 \mathrm{~mL}$ sample or standard $($ at $\mathrm{pH}=6)$ loading at $2.0 \mathrm{~mL} \mathrm{~min}^{-1}$ followed by analyte elution with $3 \mathrm{~mL}$ of HCl $1 \mathrm{~mol} \mathrm{~L}^{-1}$. In these conditions, the enrichment factor was 17 times. The calibration curves were built ranging from 5 to $50 \mu \mathrm{u} \mathrm{L}^{-1} \mathrm{Cu}^{2+}$. The procedure was applied for the analysis of fresh water sample spiked with $10 \mu \mathrm{g} \mathrm{L}^{-1} \mathrm{Cu}^{2+}$, resulting in a recovery higher than $94 \%$. Additionally, inter-column reproducibility ( $R S D<3,5 \% ; n=5$ columns) and the limit of detection of $0.8 \mu \mathrm{L} \mathrm{L}^{-1}$ were considered appropriate by taking into the maximum permitted Cu levels by the Brazilian National Environment Council (CONAMA) of $9 \mu \mathrm{L} \mathrm{L}^{-1}$ (fresh water, Class 1). The proposed approach using CA columns is a reliable and lower cost alternative for single-stage $\mathrm{Cu}$ preconcentration prior to F AAS measurements and can be recommended for the analysis of river fresh waters. CA column re-usability was confirmed up to 100 adsorption-desorption cycles.

Keywords: Copper, alginate, preconcentration, atomic absorption, water

\section{INTRODUCTION}

Copper is an essential element for the maintenance of biological functions in bacteria, plants, fungi and mammals [1]. Particularly in humans, it is an essential element that is a component of several proteins and metalloenzymes, playing substantial roles on metabolic processes, such as immune system, hemoglobin production, and collagen synthesis [2-4]. The dietary reference intake varies from 1.5 to $4 \mathrm{mg} /$ day and is practically sourced by food and drinking water in most countries [4]. Copper deficiency is characterized by body growth delay, anemia, hair and weight loss, central nervous system and cardiovascular disorders, osteoporosis, among other metabolic dysfunctions [4]. On the other hand, chronic exposure may cause nausea, vomiting, abdominal pain and diarrhea [5]. Acute exposures 
caused mostly by accidental intakes may cause liver and kidneys failures [5]. Thus, Cu determination in natural and drinking waters is of environmental and public health concern. The Brazilian National Environment Council (CONAMA), establishes the maximum allowed $\mathrm{Cu}$ concentration in fresh water (Class 1) as $9 \mu \mathrm{L} \mathrm{L}^{-1}[6]$.

Copper determination in natural waters is generally performed by instrumental techniques such as inductively coupled plasma mass spectrometry (ICP-MS), inductively coupled plasma optical emission spectrometry (ICP OES), graphite furnace atomic absorption spectrometry (GF AAS) and flame atomic absorption spectrometry (FAAS) [7]. ICP-MS and ICP OES instrumentation provide appropriate limits of detection (LOD) at the $\mathrm{ng} \mathrm{L}^{-1}$ and $\mu \mathrm{g} \mathrm{L}^{-1}$ range, respectively. Additionally, both techniques offer attractive features such as simultaneous and multielement capability, and, in the case of ICP-MS, the possibility to obtain useful isotopic information [8]. However, F AAS instrumentation involves a much simpler methodology and can be a reliable alternative for laboratories intended to quality control of fresh water. Besides simplicity, F AAS presents additional features, such as relatively high analytical throughput for single elemental analysis (e.g., about 3-4 samples/min), high tolerance of total dissolved solids (e.g., $5 \%$ ), and robustness. Notwithstanding, the relatively poor LOD of F AAS, inherent of its characteristic concentration of $0.03 \mathrm{mg} \mathrm{L}^{-1}$ at $324.8 \mathrm{~nm}$ absorption line [7], impairs reliable measurements at low Cu concentrations (e.g., <0.1 mg L-1). Therefore, precise and accurate Cu measurements by F AAS at the aforementioned concentration levels can only be achieved after preconcentration procedures, which can be carried out by using different approaches, such as solid phase extraction (SPE), cloud-point extraction [9], ionic liquids [10,11], dispersive liquid-liquid microextraction [12,13], among others. These strategies not only improve analyte detectability, but also are relevant for removing matrix components that may induce inaccurate measurements [14]. Several biosorbents have been used as a substrate for dissolved Cu separation and preconcentration, such as banana peel [15,16], corn silk [17], olive pomace [18], food waste biomass [19], peat [20], pinion shell [21], soybean hull [22], among others. They have been considered reliable and environmental-friendly alternatives to the aforementioned commercially available synthetic sorbents [23]. These materials are generally framed from biopolymers (e.g., cellulose, alginate, xanthan and chitosan) containing active binding sites, such as amine, amide, carboxylate, hydroxyl, thiol, that can interact with metallic ions and organic molecules.

Alginic acid, a biopolymer extracted from brown seaweeds comprising of $\alpha$-L-guluronic acid (G) and $\beta$-D-mannuronic acid (M) groups has been frequently used for the separation of metallic cations (e.g., Ni [24], $\mathrm{Zn}[24], \mathrm{Pb}[24,25], \mathrm{Cu}[26,27])$ from aqueous media via a cation-exchange reaction. This substrate has been also used aiming towards the adsorption of $\mathrm{Cr}(\mathrm{VI})$ ions from aqueous solution after chemical modification [28]. Calcium alginate (CA) beads were used in batch mode for Cu preconcentration from fresh waters prior to F AAS measurements [29]. At the same fashion, CA beads were used for rare earth elements (REEs) preconcentration from fresh waters prior to their determination by ICP OES [30]. Most recently, on-line analyte preconcentration was achieved using a flow-injection system incorporating a column filled with CA microparticles (< $180 \mu \mathrm{m}$ diameter) prior to 14 REEs determination in fresh waters by ICP-MS [14]. This strategy provided significant advantages in terms of analytical performance when compared to CA beads (in the $\mathrm{mm}$ diameter range) in the batch mode, since it provides faster sample loading and less possibilities of losses and contamination. CA microparticles present relatively high adsorption capacity and desorption rate, good stability for repeated use and relatively low cost (i.e., <US\$ $0.50 \mathrm{~g}^{-1}$ ) [14]. Notwithstanding, as well as for commercially-available iminodiacetate- and sulfonate-based resins, CA microparticles present non-selective adsorptive properties, which provides a wider range of potential elements for preconcentration.

This work evaluates the potentialities of CA microparticles as a substrate for a single-stage separation and preconcentration of $\mathrm{Cu}$ dissolved in fresh water for determination by $\mathrm{F}$ AAS. A set of separation columns containing $300 \mathrm{mg}$ of CA microparticles was assembled, and analyte adsorption and desorption were optimized aiming towards the highest enrichment factor. The analytical capabilities and limitations of the proposed procedure were discussed by considering the main analytical figures of merit. 


\section{MATERIALS AND METHODS \\ Reagents and solutions}

Alginic acid solution was prepared by dissolving alginic acid sodium salt (Sigma 180947, M-to-G ratio $=1.56, M_{\mathrm{w}}$ from 120000 to $190000 \mathrm{~g} \mathrm{~mol}^{-1}$ ) in deionized water (DIW) under constant stirring for $12 \mathrm{~h}$. $\mathrm{CaCl}_{2}$ was sourced by Merck (Darmstadt, Germany).

High-purity DIW (resistivity $>18.2 \mathrm{M} \Omega \mathrm{cm}$ ) was obtained from a Milli-Q ${ }^{\circledR}$ water purification system (Millipore, Belford, USA). High-purity $\mathrm{HCl}$ and $\mathrm{HNO}_{3}$ were purchased from Merck (Darmstadt, Germany). Tritisol $1000 \mathrm{mg} \mathrm{L}^{-1} \mathrm{Cu}$ standard solution was sourced from Merck (Darmstadt, Germany).

All the glassware was soaked in $\mathrm{HNO}_{3} 10 \%(\mathrm{v} / \mathrm{v})$ solution overnight and rinsed with DIW prior to use.

\section{Calcium alginate column}

Spherical CA hydrated beads (ca. $3 \mathrm{~mm}$ diameter) were synthesized by adding a $1.0 \%(\mathrm{w} / \mathrm{v}$ ) alginic acid solution drop wise to a $4.0 \%(\mathrm{w} / \mathrm{v}) \mathrm{CaCl}_{2}$ solution under constant stirring, as recommended elsewhere [31]. Thereafter, CA microparticles (from 10 to $180 \mu \mathrm{m}$ ) were obtained after cryogenic grinding for $10 \mathrm{~min}$ dried CA beads (ca. $1 \mathrm{~mm}$ diameter) [14]. For column separation, $300 \mathrm{mg}$ CA microparticles was dispersed in $2 \mathrm{~mL}$ of DIW and transferred into a polypropylene column $(0.8 \mathrm{~cm}$ internal diameter; Eichrom Technologies Inc., Darien, IL, USA) with a porous polyethylene frit at the bottom, resulting in a ca. $2 \mathrm{~cm}$ bed height. A second frit was placed on the top of the CA microparticles bed to avoid particle re-suspension during solution loading. The column was coupled to a flow injection system composed of a peristaltic pump (Ismatec, Switzerland), Tygon ${ }^{\circledR}$ and PTFE tubing, and silicone sleeves (Figure 1).

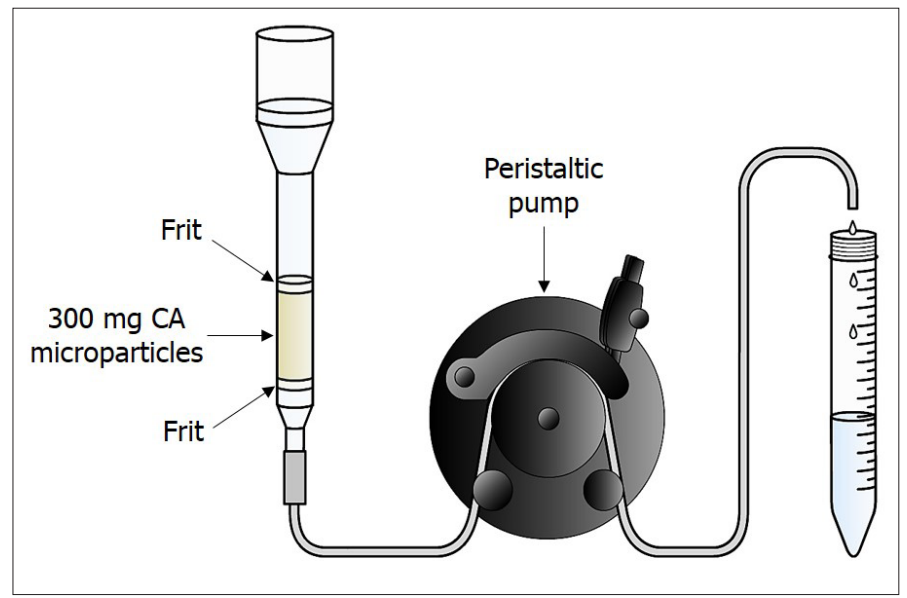

Figure 1. Column separation manifold.

\section{Cu adsorption}

Tap water samples were collected at the Institute of Chemistry of the University of São Paulo (São Paulo, Brazil). Laboratory samples were collected with Teflon bottles, filtered through $0.45 \mathrm{~mm}$ pore diameter cellulose acetate membrane (Millipore, Belford, USA), acidified with $\mathrm{HNO}_{3}$ to $\mathrm{pH} 1.60$, and stored in Teflon bottles before preconcentration.

Parameters affecting $\mathrm{Cu}$ preconcentration such as $\mathrm{pH}$ (from 0 to 8 ), sample loading flow rate (from 0.5 to $2 \mathrm{~mL} \mathrm{~min}^{-1}$ ), eluting $\mathrm{HCl}$ concentration (from 0.01 to $1 \mathrm{~mol} \mathrm{~L}^{-1}$ ) and corresponding volume (from 1 to $5 \mathrm{~mL}$ ) were monoparametrically evaluated aiming towards the highest analyte enrichment factor.

Adsorption efficiency $(Q)$, adopted as the percentage of removed analytes from test samples, was calculated through the Equation 1:

$$
Q(\%)=\frac{C_{0}-C_{i}}{C_{0}} \times 100 \quad \text { Equation } 1
$$


where $C_{0}$ is the initial concentration of analytes in the test samples and $C_{i}$ is the concentration of analytes in remaining sample matrix solution after passing through the column.

\section{FAAS instrumentation}

An AAS Vario 6 Flame Atomic Absorption Spectrometer (Analytik Jena, Jena, Germany) equipped with copper hollow-cathode lamp, as radiation source for absorbance measurements at $324.8 \mathrm{~nm}$, operating at $4 \mathrm{~mA}$, deuterium background correction lamp and integrated autosampler (Analytik Jena AS51) were used. Operating parameters were adjusted according to the manufacturer's recommendations, and consisted of $0.8 \mathrm{~nm}$ slit width, air flow rate $361 \mathrm{~L} \mathrm{~h}^{-1}, \mathrm{C}_{2} \mathrm{H}_{2}$ flow rate $50 \mathrm{~L} \mathrm{~h}^{-1}$.

Limit of detection (LOD) of the proposed procedure was calculated through the Equation 2:

$$
L O D=\frac{3 \times \sigma}{\alpha} \quad \text { Equation } 2
$$

where $\sigma$ is the standard deviation of the blank and $\alpha$ is the slope of the calibration curve.

\section{Characterization of calcium alginate substrate}

The adsorption isotherms of $\mathrm{Cu}$ onto CA microparticles were obtained at $(24 \pm 1){ }^{\circ} \mathrm{C}$ and $\mathrm{pH} 6.0$, in the concentration range of 1.0 to $200 \mathrm{mg} \mathrm{L}^{-1}$ in order to determine the adsorption capacity. The mass of CA microparticles and the Cu solution volume were kept constant as $10 \mathrm{mg}$ and $1 \mathrm{~mL}$, respectively. After reaching equilibrium conditions, the supernatants were separated from the substrate and further analyzed by F AAS. The concentration of adsorbed $\mathrm{Cu}$ onto the particles was determined as the difference between the initial concentration $\left(\mathrm{C}_{0}\right)$ and its concentration in the supernatants, or the equilibrium concentration $\left(\mathrm{C}_{\mathrm{e}}\right)$. The adsorption capacity of $\mathrm{Cu}$ was calculated dividing the concentration of adsorbed $\mathrm{Cu}$ by the mass of CA microparticles $(\mathrm{m})$ and multiplying by the solution volume (v) (Equation 3 ):

$$
\mathrm{q}_{e}=\frac{C_{0}-C_{e}}{m} \times v
$$

Equation 3

where $\mathrm{q}_{e}\left(\mathrm{mg} \mathrm{g}^{-1}\right)$ is the adsorption capacity of $\mathrm{Cu}$.

The Langmuir, Freundlich and Dubinin-Radushkevitch (D-R) models [32] were applied to evaluate the adsorption process.

About $10 \mathrm{mg}$ of CA microparticles and $10 \mathrm{~mL}$ of $2 \mathrm{~g} \mathrm{~L}^{-1} \mathrm{Cu}^{2+}$ solution at $\mathrm{pH}=6$ were shaken overnight in order to saturate the substrate before scanning electron microscopy (SEM) imaging. The morphology of CA microparticles was analyzed by using a model FEG-SEM JEOL JSM 7401 equipment. Dried CA microparticles were coated with a thin $(\sim 2 \mathrm{~nm})$ gold layer prior to the analyses.

\section{RESULTS AND DISCUSSION}

\section{Analyte adsorption}

Adsorption $\mathrm{pH}$ is a key variable for obtaining quantitative analyte preconcentration, since the cationexchange reactions between carboxylates of the alginate matrix and $\mathrm{Cu}$ ions are dependent on the availabilities of $\mathrm{H}^{+}, \mathrm{Ca}^{2+}$ (from the substrate), $\mathrm{Cu}^{2+}$, and -COO- groups.

The influence of $\mathrm{pH}$ (from 0 to 8 ) on $\mathrm{Cu}$ adsorption was evaluated, in batch mode, using a $10 \mathrm{~mL}$ of $1.0 \mathrm{mg} \mathrm{L}^{-1} \mathrm{Cu}^{2+}$ standard solution and $100 \mathrm{mg}$ of dried beads (ca., $1 \mathrm{~mm}$ diameter). The system was shaken overnight to ensure equilibrium, and the $\mathrm{Cu}$ concentration in the supernatant was further determined by F AAS. No Cu adsorption (i.e., $Q=0$ ) was observed at $\mathrm{pH}=0$. A substantial increase in analyte adsorption efficiency was achieved when the solution $\mathrm{pH}$ was increased from 1 to 2 , reaching a plateau of ca. $100 \% \mathrm{Q}$ at $\mathrm{pH}$ values ranging from 4 to 8 . This relatively wide adsorption $\mathrm{pH}$ range 
(i.e., from 4 to 8 ) indicates there is no need to buffer test samples before sample loading, minimizing the possibilities of contamination. The influence of $\mathrm{pH}$ on $\mathrm{Cu}$ adsorption onto $\mathrm{CA}$ beads was in close agreement with previous findings, where in maximum $\mathrm{Cu}$ adsorption was attained at $\mathrm{pH}=5[26,29]$. As expected, CA beads and microparticles presented the same adsorption behavior in terms of $\mathrm{pH}$; therefore, further experiments were performed with CA column (containing $300 \mathrm{mg}$ CA microparticles) conditioned with DIW at $\mathrm{pH}=6$.

The influence of sample loading flow rate (from 0.5 to $2 \mathrm{~mL} \mathrm{~min}^{-1}$ ) was evaluated with a $1 \mathrm{mg} \mathrm{L}^{-1}$ $\mathrm{Cu}$ standard solution at $\mathrm{pH}=6$. Quantitative analyte adsorption on the CA column was obtained when samples were loaded at flow rates of up to $2 \mathrm{~mL} \mathrm{~min}^{-1}$, as the concentrations $(\mathrm{Ci})$ of $\mathrm{Cu}$ in the remaining sample matrix solution, after passing through the column, were below the F AAS LOD (i.e., $50 \mu \mathrm{g} \mathrm{L}^{-1}$ ).

After defining the best adsorption conditions, isotherm experiments were carried out for determining the adsorption capacity of $\mathrm{Cu}$ by the CA microparticles. Parameters predicted from (a) nonlinear fittings for Langmuir and Freundlich models and linear fitting for Dubinin-Radushkevitch are presented in Table I. No plateau was observed in the $\mathrm{Cu}$ isotherm, indicating that the CA substrate was no longer saturated. The experimental data fitted the Langmuir and Freundlich models (Figure 2a). The $q_{\max }$ value of $6.49 \mathrm{~g} \mathrm{~g}^{-1}$ predicted by Langmuir model was 3 orders of magnitude higher than that reported by Singh et al., wherein a $q_{\max }$ value of $5 \mathrm{mg} \mathrm{g}^{-1}$ was obtained for $\mathrm{Cu}^{2+}$ adsorption onto calcium alginate beads [26].

Table I. Equilibrium adsorption of $\mathrm{Cu}$ onto CA microparticles. Parameters predicted from (a) nonlinear fittings for Langmuir and Freundlich models, and (b) linear fitting for Dubinin-Radushkevitch corresponding to each adsorption model

\begin{tabular}{ccc}
\hline Langmuir & Freundlich & Dubinin-Radushkevitch \\
\hline$q_{\max }=6.49 \mathrm{~g} \mathrm{~g}^{-1}$ & $n=1.2359$ & $q_{\max }=1.43 \mathrm{~g} \mathrm{~g}^{-1}$ \\
$K_{L}=2.56 \times 10^{-4} \mathrm{~L} \mathrm{mg}^{-1}$ & $K_{F}=1.0288\left(\frac{m g}{L \times g}\right) /\left(\frac{m g}{L \times g}\right)^{\frac{1}{n}}$ & $E_{a}=4.45 \mathrm{~kJ} \mathrm{~mol}^{-1}$ \\
$r^{2}=0.9704$ & $r^{2}=0.9813$ & $r^{2}=0.9691$ \\
\hline
\end{tabular}
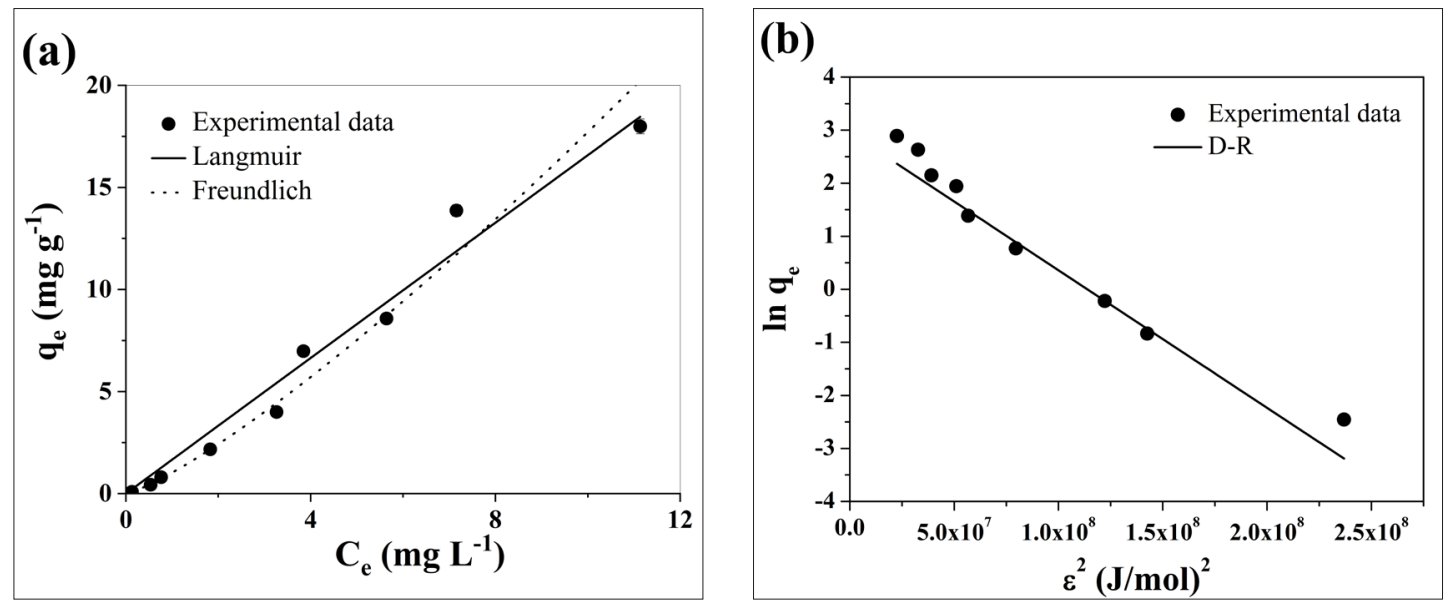

Figure 2. Adsorption isotherm of Cu solution on CA microparticles along with (a) nonlinear fittings for Langmuir and Freundlich models, and (b) linear fitting for Dubinin-Radushkevitch (D-R).

Additionally, the experimental adsorption data fitted well the D-R model (Figure $2 b$ ), which is described by the linearized form (Equation 4) in which appropriate correlation coefficient of 0.9691 was obtained: 


$$
\ln q_{e}=\ln q_{\max }-\beta \varepsilon^{2} \quad \text { Equation } 4
$$

where $\varepsilon=R T \ln \left[1+1 / C_{e}\right]\left(\mathrm{J} \mathrm{mol}^{-1}\right)$ is the Polanyi potential, $R$ is the gas constant $\left(8.314 \mathrm{~J} \mathrm{~mol}^{-1} \mathrm{~K}^{-1}\right)$ and $T$ is temperature. The plot of $\ln q_{e}$ as a function of $\varepsilon^{2}$ yields $q_{\max }$ (intercept) and $\beta$ (slope). $\beta$ value is related to the mean free energy of adsorption $\left(E_{a}, \mathrm{~kJ} \mathrm{~mol}^{-1}\right)$, Equation 5 :

$$
E_{a}=\frac{1}{\sqrt{2 \beta}}
$$

Equation 5

The values of the D-R fitting parameters $q_{\max }$ and $E_{a}$ amounted to $1.43 \mathrm{~g} \mathrm{~g}^{-1}$ and $4.45 \mathrm{~kJ} \mathrm{~mol}^{-1}$, respectively. The magnitude of the adsorption energy indicated a strong affinity, as expected for electrostatic interaction among the negatively charged CA microparticles surface and $\mathrm{Cu}^{2+}$ cations [14]. Although the adsorption capacity predicted by D-R model be smaller than that from Langmuir, at the diluted concentration range (i.e., from 1 to $200 \mathrm{mg} \mathrm{L}^{-1}$ ), both values are considered appropriate and demonstrate the high affinity of $\mathrm{Cu}^{2+}$ ions to the CA substrate.

The adsorption of $\mathrm{Cu}$ on $\mathrm{CA}$ microparticles led to substantial changes in the morphological characteristics of the particles' surface. SEM images revealed the smooth surface of CA microparticles (Figure $3 a$ ), which turned rough after $\mathrm{Cu}$ adsorption (Figure $3 \mathrm{~b}$ ). Additionally, Figure $3 \mathrm{~b}$ suggests that smaller particles were clustered into larger ones, probably mediated by $\mathrm{Cu}^{2+}$ ions.
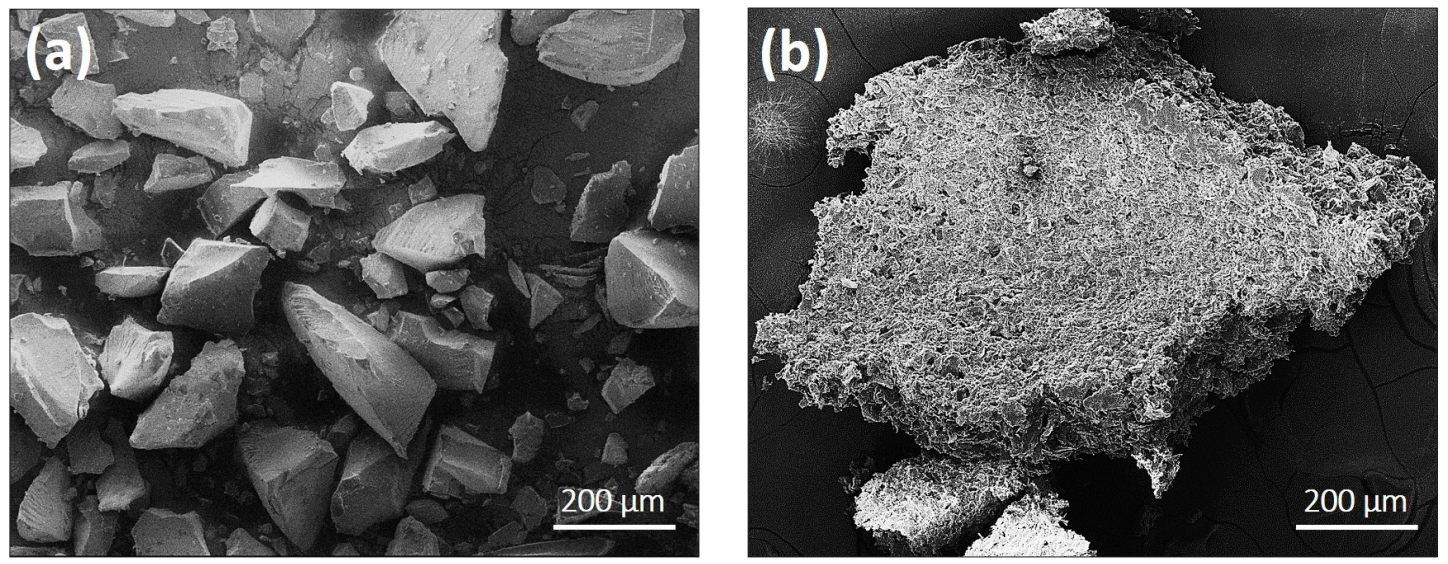

Figure 3. Scanning electron microscopic images of CA microparticles (a) before and (b) after Cu adsorption. Experimental conditions: $10 \mathrm{mg} \mathrm{CA}$ substrate $+10 \mathrm{~mL}$ of $2 \mathrm{~g} \mathrm{~L}^{-1} \mathrm{Cu}^{2+}$ at $\mathrm{pH}=6$.

\section{Analyte desorption}

Preliminary experiments demonstrated that $\mathrm{HCl}$ and $\mathrm{HNO}_{3}$ presented similar desorption behavior, and $\mathrm{HCl}$ was selected because chlorine ions induce $\mathrm{Cu}$ complexation enhancing desorption. The influence of eluting $\mathrm{HCl}$ concentration (from 0.01 to $1.0 \mathrm{~mol} \mathrm{~L}^{-1}$ ) and corresponding volume (from 1 to $5 \mathrm{~mL}$ ) were evaluated after loading $10 \mathrm{~mL}$ of $1 \mathrm{mg} \mathrm{L}^{-1} \mathrm{Cu}^{2+}$ standard solution at $\mathrm{pH}=6$ onto CA microparticles column. Quantitative analyte desorption was obtained when $3 \mathrm{~mL}$ of $\mathrm{HCl} 1.0 \mathrm{~mol} \mathrm{~L}^{-1}$ was used, at 0.5 $\mathrm{mL} \mathrm{min}^{-1}$. By loading the column with a $50 \mathrm{~mL}$ test portion, the procedure provided an enrichment factor 17-fold. The optimized condition for Cu preconcentration is summarized in Table II. 
Table II. Procedure for CA microparticles column conditioning

\begin{tabular}{|c|c|}
\hline Step & Procedure \\
\hline Conditioning & $15 \mathrm{~mL}$ of $\mathrm{DIW} \mathrm{pH}=6$ \\
\hline Sample loading & $50 \mathrm{~mL}$ of sample or copper standard solution $(\mathrm{pH}=6)$ \\
\hline Analyte elution & $3 \mathrm{~mL}$ of $\mathrm{HCl} 1 \mathrm{~mol} \mathrm{~L}^{-1}$ \\
\hline Rinsing & $10 \mathrm{~mL}$ of $\mathrm{DIW}+2 \mathrm{~mL}$ of $\mathrm{HCl} 1 \mathrm{~mol} \mathrm{~L}^{-1}$ \\
\hline
\end{tabular}

\section{Analytical features}

The inter-column reproducibility was evaluated by using 5 independent columns containing 300 $\mathrm{mg}$ dried CA microparticles. After loading $50 \mathrm{~mL}$ of $10 \mu \mathrm{g} \mathrm{L}^{-1} \mathrm{Cu}$ standard solutions in each column, loading at $2.0 \mathrm{~mL} \mathrm{~min}^{-1}$, the adsorbed $\mathrm{Cu}^{2+}$ ions were eluted with $3 \mathrm{~mL}$ of $1.0 \mathrm{~mol} \mathrm{~L}^{-1} \mathrm{HCl}$ solution, and the obtained enriched solutions were analyzed by F AAS. Under these conditions, coefficient of variation of $\mathrm{Cu}$ determinations (i.e., inter-column reproducibility) was $3.4 \%(n=5)$, and was fit for the intended purpose. These findings demonstrate that sample throughput can be significantly increased by assembling a set of analytical CA columns, allowing the processing of several calibrating and test samples simultaneously.

Figure 4 presents a calibration curve of Cu obtained by F AAS in the concentration range from 5 to $50 \mathrm{ng} \mathrm{g}^{-1}$. The high correlation coefficient $\left(r^{2}=0.9999\right)$ demonstrates the reliability and robustness of the proposed preconcentration procedure, since each calibration point was obtained with one independent column.

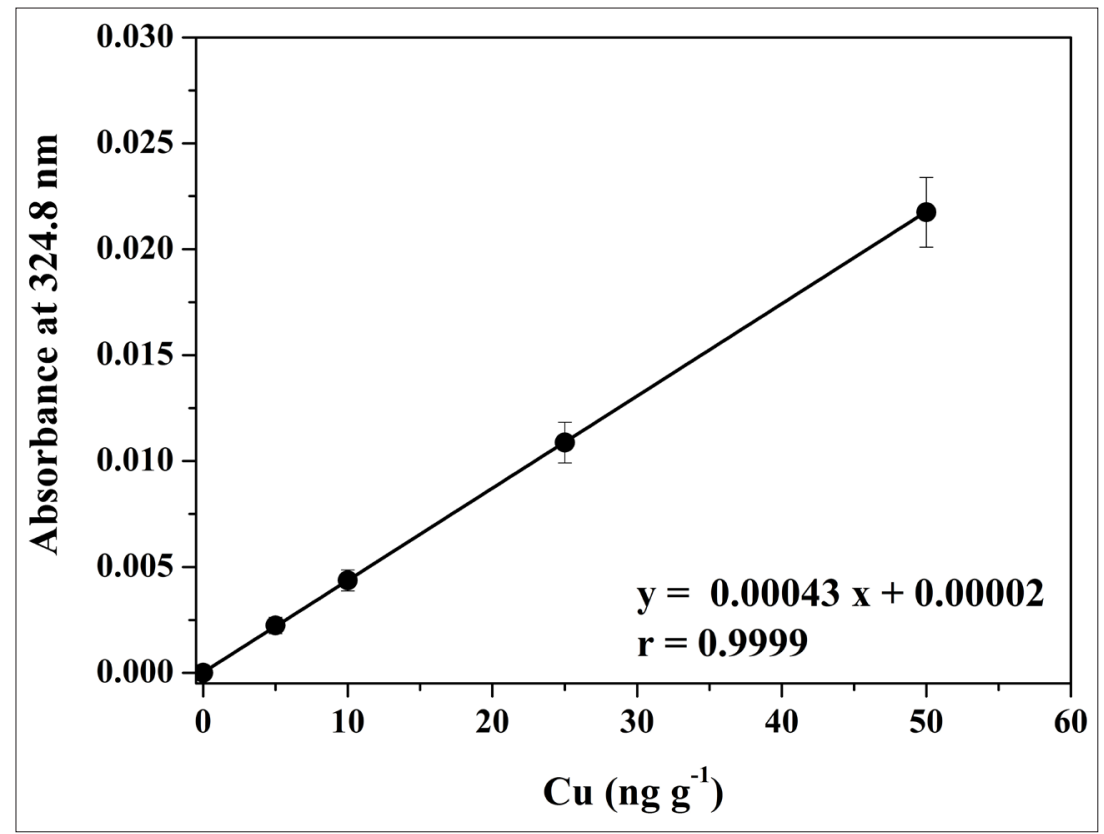

Figure 4. Calibration curve for $\mathrm{Cu}^{2+}$ obtained with the proposed procedure. Calibration points were obtained simultaneously using 5 different columns. Error bars correspond to \pm the standard deviation ( $n=3$ measurements).

\section{Spike and Recovery}

The proposed preconcentration procedure, which is described in Table II, was applied to the analysis of tap water test sample, which was collected at the Institute of Chemistry of the University of São Paulo (São Paulo, Brazil). The measured Cu concentration in the tap water was $1.04 \pm 0.10 \mu \mathrm{g} \mathrm{L}^{-1}$, which 
was close to the LOD of the method (i.e., $0.8 \mu \mathrm{g} \mathrm{L}^{-1}$ ). That was the reason for such high measurement uncertainty. Recovery from the analysis of a $50 \mathrm{~mL}$ tap water spiked with $10 \mathrm{\mu g} \mathrm{L}^{-1} \mathrm{Cu}$ standard solution was $94 \pm 4.7 \%(n=3)$, and was considered appropriate for the intended purpose (i.e., acceptable range: between 90 and $110 \%$ ). In spite of the presence of matrix concomitants (e.g., $\mathrm{Na}^{+}, \mathrm{K}^{+}, \mathrm{Ca}^{2+}$, $\mathrm{Mg}^{2+}$, $\mathrm{NO}_{3}^{-}, \mathrm{SO}_{4}{ }^{2-}, \mathrm{CO}_{3}{ }^{2-}, \mathrm{Cl}^{-}$), the high affinity between $\mathrm{Cu}^{2+}$ and $\mathrm{CA}$ beads provided reasonable recoveries. Additionally, the LOD of $0.8 \mu \mathrm{g} \mathrm{L}^{-1}$ was below to the appropriate by taking into account the maximum permitted $\mathrm{Cu}$ levels in fresh water by the Brazilian National Environment Council (CONAMA) of $9 \mu \mathrm{g} \mathrm{L}^{-1}$ [6].

The CA column could be properly regenerated after rinsing with $10 \mathrm{~mL}$ of DIW $+2 \mathrm{~mL}$ of HCl $1 \mathrm{~mol} \mathrm{~L}^{-1}$ and conditioning with $15 \mathrm{~mL}$ of DIW at $\mathrm{pH}=6$. This procedure allowed the re-utilization of the CA column for up to 100 times (i.e., adsorption-desorption cycles) procedures.

For comparison, Table III presents a comparison of the analytical features of the proposed method and selected preconcentration methods using different biosorbents already published in the literature, that are aimed at the determination of $\mathrm{Cu}$ in fresh waters by F AAS. Most analytical features such as enrichment factor, LOD and measurement precision are in the same magnitude as those reported in the literature (especially peat and soybean hull), and they are considered appropriated for the intended purpose. Additionally, the reusability of the CA substrate is a remarkable advantage, as it can be used for more than 100 cycles without any loss of performance.

Table III. Analytical features of selected preconcentration methods for the determination of $\mathrm{Cu}$ in fresh waters by FAAS. EF = enrichment factors, LOD = limit of detection, RSD = percentage relative standard deviation; $\operatorname{Rec}=$ recovery based on the analysis of spiked test samples, n.i. $=$ not informed.

\begin{tabular}{lcccccc}
\hline Material & EF & LOD $\left(\boldsymbol{\mu g ~ \mathbf { ~ L } ^ { - 1 } )}\right.$ & RSD (\%) & Rec (\%) & Re-use & Reference \\
\hline Banana peel & 20 & n.i. & n.i. & 100 & 11 & {$[15]$} \\
Corn silk & 39 & 0.35 & 1.6 & 99 & 50 & {$[17]$} \\
Olive pomace & 30 & 0.042 & $0.75-10$ & 87 & n.i. & {$[18]$} \\
Peat & 16 & 3 & 3.3 & 100 & $>100$ & {$[20]$} \\
Soybean hull & 18 & 0.8 & n.i. & 99 & 30 & {$[22]$} \\
Calcium alginate & n.i. & n.i. & $4.0-8.0$ & 91 & n.i. & {$[29]$} \\
Calcium alginate & 17 & 0.8 & 3.5 & 94 & $>100$ & Present work \\
\hline
\end{tabular}

\section{CONCLUSIONS}

CA microparticles is a reliable substrate for $\mathrm{Cu}$ preconcentration from freshwater. The optimized preconcentration procedure could be successfully applied to the analysis of tap water, in which the analytical features such as reproducibility, accuracy and LOD were considered appropriate for the intended purpose. The CA substrate is a reliable and environmentally-friendly alternative to commercially available resins and can be recommended for $\mathrm{Cu}$ preconcentration aiming at $\mathrm{F}$ AAS measurements. It provides a high adsorption capacity and good stability for repeated use.

\section{Acknowledgments}

The authors gratefully acknowledge financial support from Fundação de Amparo à Pesquisa do Estado de São Paulo (FAPESP; Grants 2015/06161-1 and 2017/22599-2) and from Conselho Nacional de Desenvolvimento Científico e Tecnológico (CNPq; Grants 306848/2017-1 and 308930/2017-7).

Manuscript submitted: Dec. 23, 2018; revised manuscript submitted: March 25, 2019; manuscript accepted: April 11, 2019; published online: July 15, 2019. 


\section{REFERENCES}

1. Festa, R. A.; Thiele, D. J. Curr. Biol., 2011, 21, pp R877-R883.

2. Djoko, K. Y.; Ong, C. L.; Walker, M. J.; McEwan, A. G. J. Biol. Chem., 2015, 290, pp 1854-1861.

3. Kim, B.-E.; Nevitt, T.; Thiele, D. J. Nat. Chem. Biol., 2008, 4, pp 176-185.

4. Kabata-Pendias, A.; Mukherjee, A. B. Trace Elements from Soil to Human, Springer-Verlag, Berlin, 2007.

5. Council, N. R. Committee on Copper in Drinking Water, The National Academies Press, Washington, DC, 2000.

6. CONAMA, Resolution 430, May 13, 2011, Provisions the conditions and standards of effluents and complements and changes Resolution 357 from March 17, 2005 issued by the National Environment Council (CONAMA). Published in Official Gazette 92 on May 16, 2011.

7. Welz, B.; Sperling, M. Atomic Absorption Spectrometry, Wiley-VCH Verlag GmbH, Weinhcini, $3^{\text {rd }}$ edition, 1999.

8. Montaser, A.; Golightly, D. W. Inductively coupled plasmas in analytical atomic spectrometry, VCH Publisher, New York, 1988.

9. Gouda, A. A.; Amin, A. S. Spectrochim. Acta Part A, 2014, 120, pp 88-96.

10. Zare-Shahabadi, V.; Asaadi, P.; Abbasitabar, F.; Shirmardi, A. J. Braz. Chem. Soc., 2017, 28, pp 887-894.

11. Khayatian, G.; Hassanpour, M. Anal. Bioanal. Chem. Res., 2018, 5, pp 11-21.

12. Shrivas, K.; Jaiswal, N. K. Food Chem., 2013, 141, pp 2263-2268.

13. Kanberoglu, G. S.; Yilmaz, E.; Soylak, M. J. Iranian Chem. Soc., 2018, 15, pp 2307-2314.

14. Arantes de Carvalho, G. G.; Petri, D. F. S.; Oliveira, P. V. Anal. Meth., 2018, 10, pp 4242-4250.

15. Castro, R. S. D.; Caetano, L.; Ferreira, G.; Padilha, P. M.; Saeki, M. J.; Zara, L. F.; Martines, M. A. U.; Castro, G. R. Ind. Eng. Chem. Res., 2011, 50, pp 3446-3451.

16. Ahmad, Z.; Gao, B.; Mosa, A.; Yu, H.; Yin, X.; Bashir, A.; Ghoveisi, H.; Wang, S. J. Clean. Prod., 2018, 180, pp 437-449.

17. Zhu, X.; Yu, H.; Jia, H.; Wu, Q.; Liu, J.; Li, X. Anal. Meth., 2013, 5, pp 4460-4466.

18. El-Sheikh, A. H.; Sweileh, J. A.; Saleh, M. I. J. Hazard. Mater., 2009, 169, pp 58-64.

19. Ince, M.; Ince, O. K.; Asan, E.; Onal, A. At. Spectrosc., 2017, 38, pp 142-148.

20. Gonzáles, A. P. S.; Firmino, M. A.; Nomura, C. S.; Rocha, F. R. P.; Oliveira, P. V.; Gaubeur, I. Anal. Chim. Acta, 2009, 636, pp 198-204.

21. Calero, M.; Blázquez, G.; Dionisio-Ruiz, E.; Ronda, A.; Martín-Lara, M. A. Desalin. Water Treat., 2013, 51, pp 2411-2422.

22. Xiang, G.; Zhang, Y.; Jiang, X.; He, L.; Fan, L.; Zhao, W. J. Hazard. Mater., 2010, 179, pp 521525.

23. Teixeira, L. S. G.; Lemos, V. A.; Coelho, L. M.; Rocha, F. R. P. Appl. Spectrosc. Rev., 2016, 51, pp 36-72.

24. Nastaj, J.; Przewłocka, A.; Rajkowska-Myśliwiec, M. Polish J. Chem. Technol., 2016, 18, pp 81-87.

25. Ren, H.; Gao, Z.; Wu, D.; Jiang, J.; Sun, Y.; Luo, C. Carbohyd. Polym., 2016, 137, pp 402-409.

26. Singh, L.; Pavankumar, A. R.; Lakshmanan, R.; Rajarao, G. K. Ecol. Eng., 2012, 38, pp 119-124.

27. Kumar, R.; Kim, S.-J.; Kim, K.-H.; Kurade, M. B.; Lee, S.-h.; Oh, S.-E.; Roh, H.-S.; Jeon, B.-H. Surf. Interf. Anal., 2018, 50, pp 480-487.

28. Arantes de Carvalho, G. G.; Kelmer, G. A. R.; Fardim, P.; Oliveira, P. V.; Petri, D. F. S. Colloids Surf. A: Physicochem. Eng. Aspects, 2018, 558, pp 144-153.

29. Choi, J. M.; Choi, S. D. J. Korean Chem. Soc., 2004, 48, pp 590-598.

30. Arantes de Carvalho, G. G.; Kondaveeti, S.; Petri, D. F. S.; Fioroto, A. M.; Albuquerque, L. G. R.; Oliveira, P. V. Talanta, 2016, 161, pp 707-712.

31. Kondaveeti, S.; Cornejo, D. R.; Petri, D. F. S. Colloids Surf., B, 2016, 138, pp 94-101.

32. Foo, K. Y.; Hameed, B. H. Chem. Eng. J., 2010, 156, pp 2-10. 